\title{
Fair value measurement under Level 2 inputs: do market and transaction multiples catch firm-specific risk factors?
}

\author{
Vera Palea*, Christian Rainero ${ }^{*}$, Alessandro Migliavacca ${ }^{*}$
}

\begin{abstract}
This paper focuses on fair value measurement under the IFRS 13 assumptions and the reliability of the market and transaction multiples evaluations ("Level 2" methods). We test the reliability of multiples evaluation approaches in different economic sectors, by comparing the fair value of 1678 companies estimated by multiples with the effective market capitalization over 15 years. Multiples' fair value does not provide a reliable measure of a company's value, with a gap that varies depending upon portfolios and time. In the case of observable Level 2 fair value indicators for a market, such as market multiples, the company's fair value is not consistent with the real market value. Thus, whenever Level 2 indicators are not observable, the method is increasing volatility and intrinsic evaluation risk.
\end{abstract}

Keywords: Fair Value, Market Multiples, Transaction Multiples, Private Equity Evaluation, Accounting, Reliability

\section{Introduction}

The present work focuses on the appraisal of private equity fair value under the IFRS 13 Fair Value Measurement assumptions, building upon the previous findings of Palea and Maino (2013). Based on the assumption that, under market efficiency hypothesis, the fair value is well represented by market capitalization, Palea and Maino observe that inconsistencies arise when estimating the enterprise value of a listed company with market and transaction multiples. In particular, they assert that their "statistical analysis supports the claim that market and transaction multiples cannot provide a faithful representation of the real-world economic phenomena they purport to represent. Consistently with Kim and Ritter (1999), market and transaction multiples perform very poorly".

Market multiples and transaction multiples appraisal of the enterprise value are categorized by IFRS 13 in "Level 2" of the fair value estimation techniques hierarchy. As the two methodologies are both based on market-wide and peer analyses, the value that arises from calculation using one of the two is expected to closely approximate the real fair value of a company. The purpose of this contribution is to test if this actually holds in practice. Our research question can therefore be formulated as follows: Are market and transaction multiples capable of estimating correctly the real fair value of a company, catching firm-specific risk factors?

In order to resolve this research question, extending Palea and Maino (2013) in terms of years and number of firms included in the analysis, we set up an

\footnotetext{
* Associate Professor, Department of Economics and Statistics Cognetti de' Martiis - University of Turin - e-mail: vera.palea@unito.it

$\dagger$ Associate Professor, Department of Management - University of Turin, e-mail: christian.rainero@unito.it

\$ PostDoc Research Fellow, Department of Management - University of Turin, Corso Unione Sovietica 218/bis - IT10134 - Torino (Italy). e-mail: alessandro.migliavacca@unito.it corresponding author
} 
empirical test to compare the market capitalization and the enterprise value calculated by market and transaction multiples on a larger dataset. Specifically, we compare the fair value estimated by market and transaction multiples with the effective market capitalization over 15 years (2003-2017).

We argue that fair value as defined by IFRS 13, and evaluated by market and transaction multiples approaches, does not provide a reliable measure of the real value of a company, the difference between evaluated and real fair value varying depending upon portfolios and periods of time.

The results are significant because in the case of observable Level 2 fair value indicators, such as market multiples, the fair value is not consistent with the real market value of the equity. This raises issues regarding private equity evaluation, where Level 2 indicators are not easily observable, non-viable for catching firmspecific risk factors and potentially increasing volatility and intrinsic evaluation risk.

\section{Quality of information, fair value measurement and firm value}

From an investor's perspective, the quality of financial statement information is crucial for the investment decision making process. In particular, any estimation error that occurs in accounting information increases the information-processing costs for the users, the estimation risk premium and the investors' adverse selection. Any reduction in the quality of information of financial statements increases the cost of capital to the company (Baiman \& Verrecchia, 1996; Diamond \& Verrecchia, 1991). This, in turn, leads to a reduction in the firm's assets because of the uncertainty the investors perceive in the accounting information.

This is particularly true in the case of subjectivity of accounting information, such as in the case of estimates. In these cases, managers tend to exert their decisional power and abuse discretion, which leads to biases in their estimations (Aboody, Barth, \& Kasznik, 2006; Bartov, Mohanram, \& Nissim, 2007).

When the biases are foreseeable, investors tend to predict and consider them in the firm's value estimation; when the biases are unexpected and unpredictable, the accounting information quality deteriorates, the firm's value decreases and the investors are less capable of monitoring managerial decisions and behaviors (Bens \& Monahan, 2004; Biddle \& Hilary, 2006; Bushman \& Smith, 2001; Hope \& Thomas, 2008; Kanodia, Sapra, \& Venugopalan, 2004; Lombardo \& Pagano, 2002). This creates a vicious circle where unreliable information gradually reduces the firm's value in the mid- and long-term.

In order to reduce the information asymmetry that could arise in those cases and to improve the quality of information, the prevalent opinion held by both the standard setters and prevalent academic literature is that the best and most relevant information for financial statement users is provided by the fair value (Barth, Beaver, \& Landsman, 2001).

The fair value of any asset, as defined by both IFRS and SFAS accounting principles, is the price that would be received for the sale of that asset in an orderly transaction between market participants at the measurement date.

In 2011 the IASB issued IFRS 13 "Fair value measurement", which came into effect on January 1 1 , 2013 (International Accounting Standards Board, 2013). The standard describes a framework for fair value measurement by outlining methodology. As pointed out by IFRS 13, the fair value must be determined on a market-based and not entity-specific measurement. Thus, fair value represents an exit price and its measurement relies on the usage of evaluation approaches capable of observing the fair value from a market perspective. 
IFRS 13 establishes a hierarchy that classifies the inputs for fair value measurement in three categories:

1) Level 1 inputs: this level represents the most reliable and the most observable of the inputs for fair value measurement. At the first level, thus at the highest priority, it indicates the unadjusted quoted prices of the common shares. Generally, these are represented by market capitalization. The quoted prices of identical assets on the market are considered in this level.

2) Level 2 inputs: this level equates fair value to:

a. quoted prices for similar assets in active markets;

b. quoted prices for identical or similar assets in markets that are not active;

c. inputs other than quoted prices that are observable for the assets, such as interest rates and yield curves observable at commonly quoted intervals, volatilities, prepayment speeds, loss severities, credit risks and default rates;

d. and inputs that are derived principally from, or corroborated by, observable market data by correlation or other means.

3) Level 3 inputs: unobservable inputs, for which market data are not available. Usually those are made up of the best information available at the moment, and bring up information asymmetries between preparers of financial statements (managers) and users (investors); usually, Discounted Cash Flow and other income methods are included in this level, as they are based on internal data, projections, forecasts and estimates that are not directly observable on the market.

The extant literature highlights how the users of a financial statement prefer estimations conducted through higher input levels. In particular, investors tend to prefer cases where the fair value is estimated via Level 1 inputs rather than Level 2 inputs (Goh, Ng, \& Yong, 2009; Kolev, 2009). The same is not true between Level 2 and Level 3, where investors tend to value the two typologies of inputs similarly, in particular during market and liquidity crises (Song, Thomas, \& Yi, 2010).

Assuming that for private equity, in most cases, it is not possible to obtain Level 1 data, from an IFRS 13 perspective the Level 2 data should be preferred. This means that the company's value has to be determined on the basis of market data.

As is clear, though, private equity performance is quite different from that of public companies. Generally, private equities show lower average levels of economic returns (Moskowitz \& Vissing-Jørgensen, 2002; Quigley \& Woodward, 2002). Moreover, the distribution of the economic returns shows a great asymmetry, presenting a long right tail of good and excellent economic returns (Cochrane, 2005). Determining an average value for the "peers" of the company would thus result in the introduction of a bias, given the presence of rare-breed outliers.

This has also been pointed out by Kim and Ritter (1999) who, by testing the performance of the price-to-earnings, price-to-sales, enterprise-value-to-sales and enterprise-value-to-operating cash flow ratios, discover that the market multiples perform badly, especially when using historical data as input for the evaluation. The unreliability of these multiples has also been tested by Lie and Lie (2002) in a more general study. They find that the most commonly used market multiples (Price-toEarnings (P/E), Enterprise Value-to-Sales, Enterprise Value-to-EBIT(DA)) tend to bias the estimations by introducing valuation errors, that are not influenced by the cash levels of the company, but are greatly conditioned by the size of the company, its profitability and the extent of the intangible value. 
Along the same lines, Palea and Maino (2013) compared the "real" fair value of a company (the market capitalization, that is the price paid on the market for that precise asset at the measurement moment) with the fair value determined on "Level 2" inputs, namely the market and transaction EBITDA multiples. By analyzing both the "stock" normalized differences and the return yield, they point out that the use of market and transaction multiples introduces arbitrary and unrestrained estimation errors, and in particular overestimations. Their analysis suggests market and transaction multiples do not catch risk-specific firm factors, thus introducing implicit measurement risk in the assessment of fair value. Nonetheless, practitioners and academic researchers tend to make frequent use of market and transaction multiples to assess the fair value of a company, although concurring analyses over a large time period confirms that there is no agreement on which multiple performs best. The research that follows attempts to expand Palea and Maino (2013) analysis on a larger dataset and time period in order to provide further evidence of the reliability of Level 2 inputs.

\section{Research design, methodology and data collection}

As pointed out in literature, any evaluation method produces approximations and inherent errors. In the case of financial statements, the introduction of such errors in determining asset fair values increases volatility and reduces the quality of the information, which can trigger a vicious circle that reduces the value of the firm in the medium and long term.

As mentioned above, this paper tests the reliability of the market and transaction multiples methods of fair value measurement of private equities. Specifically, we investigate whether, even if the multiples are determined on the basis of reliable and unbiased market data, their use in the evaluation process for private equity fair value introduces great errors in the estimates.

To test the extent of the errors introduced by the market and transaction multiples in measuring fair values, we consider a sample of public companies, which we treat as if they were private. We therefore assess their fair value by using Level 2 inputs. We use market capitalization as the real fair value, which is consistent with the market efficiency hypothesis (Fama, 1970). We then compare values based on transaction and market multiples with market capitalization to test for estimation errors.

In our test, we follow the best practices implemented by practitioners in private equity fair value estimation.

First of all, we extract data for 1678 companies for the fiscal years 2003-2017 from the EIKON/DataStream database (Thomson Reuters). The companies are selected applying the following proxies: Active Public Companies; with Headquarters located in Germany, France, Italy or Spain; operating in all economic sectors, excluding financial. The analysis therefore covers all the population of non-financial firms in the four countries included in the analysis. We exclude financial firms because of their specificities, which do not allow comparison with industrial firms.

The choice of country headquarters is based on the assumption that those are the most representative of the EU economy, with a long record of listed companies and relevant information made transparently available. Also, almost all of them issue their financial statement in Euro. For each company and each fiscal year, we extract the income statement and balance sheet variables indicated in appendix A.

We created consistent portfolios of listed companies for several economic sectors, in order to evaluate the market multiples for all of the different sectors. We use the 
same classification considered by the FitchRatings "European Leveraged Finance Multiple EV-aluator” Special Report (Svantner, Conti, \& Eyerman, 2016).

The portfolios are the following:

Table 1: Portfolios considered for the analysis

\begin{tabular}{|l|c|}
\hline \multicolumn{1}{|c|}{ Portfolio } & \# of companies \\
\hline Aerospace and Defense & 19 \\
\hline Auto and Related & 55 \\
\hline Chemicals & 46 \\
\hline Consumer Products & 107 \\
\hline Diversified Manufacturing & 171 \\
\hline Diversified Services & 113 \\
\hline Energy & 54 \\
\hline Food, Beverage and Tobacco & 83 \\
\hline Gaming, Lodging and Leisure & 84 \\
\hline Healthcare & 178 \\
\hline Homebuilding, Building Materials and Construction & 106 \\
\hline Media and Entertainment & 113 \\
\hline Natural Resources & 36 \\
\hline Retail & 70 \\
\hline Technology & 297 \\
\hline Telecom and Cable & 35 \\
\hline Transportation & 47 \\
\hline Utilities & 64 \\
\hline
\end{tabular}

Source: our processing based on Svantner, Conti, and Eyerman (2016).

Consist with the methodology applied by Fitch, we calculate the market multiples for each year and each portfolio. The multiples are calculated as the median for each of the following variables:

- Price/Earnings per Share (MKT_PE) and Forward Price/Earnings per Share (MKT_PE_FWD), considering all of the companies with positive earnings;

- Enterprise Value to Sales (MKT_EV_SALES) and Forward Enterprise Value to Sales (MKT_EV_SALES__FWD);

- Enterprise Value to EBITDA (MKT_EV_EBITDA) and Forward Enterprise Value to EBITDA (MKT_EV_EBITDA_FWD), considering all of the companies with a positive $\mathbf{E B} I T \bar{D} A$;

- Enterprise Value to EBIT (MKT_EV_EBIT) and Forward Enterprise Value to EBIT (MKT_EV_EBIT_FWD), considering all of the companies with a positive EBIT.

In the case of the multiples related to EBIT and EBITDA, we proceed to subtract the net debt from - or to add the net cash and cash equivalent to the calculated fair value

Appendix B reports values for each multiple grouped by portfolios and sorted by fiscal year.

As mentioned above, transaction multiples are extracted from the Fitch special report for each portfolio. The Fitch report covers the years from 2007 to 2016 and in some cases it has null values for specific sectors in specific years where data is missing. In order to increase the significance of the data and consistent with the best practices, we assign transaction multiples to each company for each year as the mean of the measurement of the year and the previous year (where available).

We then apply a discount factor in order to determine the fair value of the minority interest. Fair values computed under the transaction multiples include a control premium, whereas we are comparing multiples with stock prices of 
single shares. We therefore assume an average control premium of $35 \%$, large yet realistic, since it is consistent with past empirical evidence (Hanouna et al. 2001). Consequently, all of the transaction-multiples-based fair values are rather conservative. We also assume different control premiums up to $\mathbf{5 0 \%}$ as a robustness check, which provide the same qualitative resultsi.

We compare the results for the estimated fair value for the different multiples with the market capitalization value. The analysis is performed both on a yearly and five-year basis. The latter is particularly interesting as it includes three different "economic cycles": a pre-crisis/moderate growth period (2003-2007), a crisis/regressive period (2008-2012) and a post-crisis/recovery period (20132017).

Appendix $\mathrm{C}$ reports the descriptive statistics for each variable and for each year/period. All the variables are correlated to the market capitalization at a statistical significance level of $\mathbf{p}<0.01$.

Furthermore, our analysis is conducted using two different perspectives. The first perspective focuses on the difference between market and transaction multiples, on the one hand, and the market capitalization, on the other hand. This analysis is conducted at a "portfolio level", this being the value that an investor should put in its own financial statements if they held the all equities included in the sample. It allows the determination of whether the market multiples under- or over-estimate the fair value. It also allows the determination of the ripple effect that the under- or over-estimation generates in the following years' profits or losses in the portfolio evaluation.

The second perspective considers the ratio between the market and transaction multiples on the one hand, and the market capitalization on the other. This allows analysis of the statistical distribution of the ratios. If the ratio is lower than 1, this indicates that the company's fair value is underestimated by the multiples in comparison with the market capitalization. If the ratio is greater than 1, this indicates that the company's fair value is overestimated by market multiples when compared to market capitalization.

We determine the moments of the distribution, and in particular quartiles, median, skewness and kurtosis, which allows testing of the level of accuracy of the market and transaction multiples method of evaluation at a single-company level.

\section{Data analysis and discussion of findings}

\subsection{Analysis of the portfolio fair values: estimation of the biases introduced by} market and transaction multiples and their effect on asset values and balance sheet

As mentioned above, we first investigate the reliability of the market multiples methods by comparing results at portfolio level. The fair value of the portfolio is calculated by summing all the fair values (market capitalization and estimated fair values) for each year. The full values are reported in Appendix D. In order to render a proper and comprehensible picture of the results, they are scaled to a common factor, by normalizing the market capitalization at the date of December $31^{\text {st }} 2003$ to 1000 and by scaling all the other values to it.

Figure 1 depicts normalized results for the "historical" multiples and their polynomial interpolation through the years, while Figure 2 shows results for "forward" multiples. At first glance, both graphs suggest that the use of market multiples estimation techniques is not reliable in most of the cases. 


\section{P/E FAIR VALUES}

The P/E market multiple (figure 1, dotted bar) shows a threefold trend. In the precrisis years (2003-2007) it shows a quite large excess value of +18 to $+26 \%$ from the market capitalization (medium gray bar). During the crisis years (2008-2012) it shows a more conservative attitude, with smaller differences of $-3.7 \%$ to $+9.5 \%$. In the post-crisis upswing the volatility is slightly exacerbated, with a $-9.8 \%$ to $+4.5 \%$ wavering in the portfolio evaluation during the period. Taken as a whole, the $\mathrm{P} / \mathrm{E}$ market multiple does not seem not capable of depicting the correct value for the portfolio, with a high volatility in the results and in the reliability.

The next table shows the percentage difference of the multiple and the standard deviation to mean ratio difference from the market capitalization.

Table 2: P/E-fair-value percent difference from market capitalization and standard deviation to mean ratio difference

\begin{tabular}{|l|l|l|l|l|l|l|l|l|l|l|l|l|l|l|}
\hline $\mathbf{2 0 0 3}$ & $\mathbf{2 0 0 4}$ & $\mathbf{2 0 0 5}$ & $\mathbf{2 0 0 6}$ & $\mathbf{2 0 0 7}$ & $\mathbf{2 0 0 8}$ & $\mathbf{2 0 0 9}$ & $\mathbf{2 0 1 0}$ & $\mathbf{2 0 1 1}$ & $\mathbf{2 0 1 2}$ & $\mathbf{2 0 1 3}$ & $\mathbf{2 0 1 4}$ & $\mathbf{2 0 1 5}$ & $\mathbf{2 0 1 6}$ & $\mathbf{2 0 1 7}$ \\
\hline \multicolumn{10}{|c|}{ \% Difference } \\
\hline+2.0 & +26.2 & +19.6 & +18.4 & +26.8 & $(3.7)$ & +9.5 & +3.8 & +2.7 & $(3.3)$ & +1.2 & $(4.0)$ & +4.5 & $(9.8)$ & $(6.0)$ \\
\hline \multicolumn{10}{|c|}{ Standard Deviation to Mean ratio difference (\%) } \\
\hline$(19.3)$ & $(14.8)$ & +26.5 & +11.4 & +19.5 & $(44.4)$ & +0.8 & $(7.2)$ & $(18.8)$ & $(15.2)$ & +4.3 & $(46.1)$ & $(31.2)$ & $(62.3)$ & $(27.3)$ \\
\hline
\end{tabular}

Source: our processing.

The $\mathrm{P} / \mathrm{E}$ forward market multiple (figure 2, dotted bar) shows a behavior that is even more volatile. The smallest differences can be found in the pre-crisis (20052007 ) and first periods of the crisis (2008-2009), with differences in the range of $4 \%$ to $+0.8 \%$. In all the other years and periods, the differences are significantly larger $(-10.6 \%$ down to $-22.9 \%)$. Moreover, the differences are not correlated to the "historical" $\mathrm{P} / \mathrm{E}$ market multiple, not even with a time lag.

Table 3: P/E-forward-fair-value percent difference from market capitalization and standard deviation to mean ratio difference

\begin{tabular}{|l|l|l|l|l|l|l|l|l|l|l|l|l|l|l|}
\hline $\mathbf{2 0 0 3}$ & $\mathbf{2 0 0 4}$ & $\mathbf{2 0 0 5}$ & $\mathbf{2 0 0 6}$ & $\mathbf{2 0 0 7}$ & $\mathbf{2 0 0 8}$ & $\mathbf{2 0 0 9}$ & $\mathbf{2 0 1 0}$ & $\mathbf{2 0 1 1}$ & $\mathbf{2 0 1 2}$ & $\mathbf{2 0 1 3}$ & $\mathbf{2 0 1 4}$ & $\mathbf{2 0 1 5}$ & $\mathbf{2 0 1 6}$ & $\mathbf{2 0 1 7}$ \\
\hline \multicolumn{10}{|c|}{ \% Difference } \\
\hline$(21.2)$ & $(8.9)$ & $(2.5)$ & $(2.4)$ & +0.8 & +0.7 & $(4.0)$ & $(18.5)$ & $(10.9)$ & $(19.3)$ & $(10.6)$ & $(21.5)$ & $(17.3)$ & $(22.9)$ & $(19.2)$ \\
\hline \multicolumn{10}{|c|}{ Standard Deviation to Mean ratio difference (\%) } \\
\hline$(69.8)$ & $(20.0)$ & +12.4 & +1.4 & +3.3 & $(26.0)$ & +6.3 & $(16.9)$ & $(17.3)$ & $(11.1)$ & +12.9 & $(36.8)$ & $(39.3)$ & $(63.7)$ & $(32.0)$ \\
\hline
\end{tabular}

Source: our processing.

\section{EV/SALES FAIR VALUES}

During 2004-2006 period, the EV/Sales multiple fair value (figure 1, squared bar) is less than 5\% higher than the market capitalization (medium gray bar). Quite the opposite during crisis and recession (2007-2013), when the market multiple severely underestimates the fair value of the enterprise, with offset peaks greater than $-10 \%$. Also, in the post-crisis period, the volatility is even greater, with rises and falls in values up to $+15.8 \%$ and down to $-9 \%$.

Table 4: EV/sales-fair-value percent difference from market capitalization and standard deviation to mean ratio difference

\begin{tabular}{|l|l|l|l|l|l|l|l|l|l|l|l|l|l|l|}
\hline 2003 & 2004 & 2005 & 2006 & 2007 & 2008 & 2009 & 2010 & 2011 & 2012 & 2013 & 2014 & 2015 & 2016 & 2017 \\
\hline \multicolumn{10}{c|}{$\%$ Difference }
\end{tabular}




\begin{tabular}{|l|l|l|l|l|l|l|l|l|l|l|l|l|l|l|}
\hline$(7.3)$ & +4.8 & +2.4 & +4.5 & $(9.1)$ & $(23.1)$ & $(8.6)$ & $(8.4)$ & $(10.5)$ & $(11.6)$ & $(6.9)$ & +6.0 & +15.8 & +3.8 & $(9.4)$ \\
\hline \multicolumn{10}{|c|}{ Standard Deviation to Mean ratio difference (\%) } \\
\hline$(32.1)$ & +16.9 & +63.8 & +62.0 & +37.7 & +23.0 & $(0.6)$ & +20.3 & +31.9 & +23.6 & +19.2 & +33.4 & +51.8 & $(4.0)$ & +11.0 \\
\hline
\end{tabular}

Source: our processing.

Again, the "forward" multiple (squared bar on figure 2) shows great deviations from the real fair value, with large variations between different years.

Table 5: EV/sales-forward-fair-value percent difference from market capitalization and standard deviation to mean ratio difference

\begin{tabular}{|l|l|l|l|l|l|l|l|l|l|l|l|l|l|l|}
\hline $\mathbf{2 0 0 3}$ & $\mathbf{2 0 0 4}$ & $\mathbf{2 0 0 5}$ & $\mathbf{2 0 0 6}$ & $\mathbf{2 0 0 7}$ & $\mathbf{2 0 0 8}$ & $\mathbf{2 0 0 9}$ & $\mathbf{2 0 1 0}$ & $\mathbf{2 0 1 1}$ & $\mathbf{2 0 1 2}$ & $\mathbf{2 0 1 3}$ & $\mathbf{2 0 1 4}$ & $\mathbf{2 0 1 5}$ & $\mathbf{2 0 1 6}$ & $\mathbf{2 0 1 7}$ \\
\hline \multicolumn{10}{|c|}{ \% Difference } \\
\hline$(3.8)$ & $(2.3)$ & $(9.5)$ & $(11.4)$ & $(19.4)$ & $(27.0)$ & $(2.3)$ & $(18.3)$ & $(18.1)$ & $(19.6)$ & $(14.8)$ & $(7.1)$ & 0.7 & $(3.9)$ & $(24.0)$ \\
\hline \multicolumn{10}{|c|}{ Standard Deviation to Mean ratio difference (\%) } \\
\hline$(37.4)$ & $(17.3)$ & +30.7 & +29.5 & +10.4 & +1.0 & $(6.7)$ & +3.2 & +10.3 & +15.9 & +12.6 & +17.9 & +23.0 & +1.3 & $(3.5)$ \\
\hline
\end{tabular}

Source: our processing.

\section{EV/EBITDA FAIR VALUES}

The EV/EBITDA multiple (figure 1, diagonal line filled bar) is one of the most acknowledged and used in practice, together with the P/E multiple. Our analysis, however, shows that, at portfolio level, the multiple performs poorly in any period and economic situation, with almost constant overestimations greater than $+15 \%$ (except from year 2003, 2013 and 2017) and up to almost $+39 \%$.

Also, the overestimations fluctuate through the years with no predictable pattern, which is consistent with Palea and Maino (2013).

Table 6: EV/EBITDA-fair-value percent difference from market capitalization and standard deviation to mean ratio difference

\begin{tabular}{|l|l|l|l|l|l|l|l|l|l|l|l|l|l|l|}
\hline $\mathbf{2 0 0 3}$ & $\mathbf{2 0 0 4}$ & $\mathbf{2 0 0 5}$ & $\mathbf{2 0 0 6}$ & $\mathbf{2 0 0 7}$ & $\mathbf{2 0 0 8}$ & $\mathbf{2 0 0 9}$ & $\mathbf{2 0 1 0}$ & $\mathbf{2 0 1 1}$ & $\mathbf{2 0 1 2}$ & $\mathbf{2 0 1 3}$ & $\mathbf{2 0 1 4}$ & $\mathbf{2 0 1 5}$ & $\mathbf{2 0 1 6}$ & $\mathbf{2 0 1 7}$ \\
\hline \multicolumn{10}{|c|}{ \% Difference } \\
\hline+14.5 & +29.5 & +39.4 & +29.1 & +17.2 & +8.8 & +38.9 & +17.2 & +32.0 & +34.2 & +7.4 & +19.8 & +19.4 & +20.4 & $(5.4)$ \\
\hline \multicolumn{10}{|c|}{ Standard Deviation to Mean ratio difference (\%) } \\
\hline$(33.8)$ & +28.5 & +142.1 & +108.2 & +87.7 & +53.4 & +0.3 & +50.7 & +26.7 & +107.0 & $(13.2)$ & +22.7 & $(14.5)$ & $(25.9)$ & $(31.6)$ \\
\hline
\end{tabular}

Source: our processing.

In this case, the EV/EBITDA forward multiple (figure 2, diagonal line filled bar) seems to perform better than the "historical" multiple, although with deviations similar to those of the other multiples. More specifically, it shows severe losses in reliability during the crisis period (2007-2012) and high volatility during the economic recovery (with fluctuations that rarely leave the "below-zero" deviation).

Table 7: EV/EBITDA-forward-fair-value percent difference from market capitalization and standard deviation to mean ratio difference

\begin{tabular}{|l|l|l|l|l|l|l|l|l|l|l|l|l|l|l|}
\hline $\mathbf{2 0 0 3}$ & $\mathbf{2 0 0 4}$ & $\mathbf{2 0 0 5}$ & $\mathbf{2 0 0 6}$ & $\mathbf{2 0 0 7}$ & $\mathbf{2 0 0 8}$ & $\mathbf{2 0 0 9}$ & $\mathbf{2 0 1 0}$ & $\mathbf{2 0 1 1}$ & $\mathbf{2 0 1 2}$ & $\mathbf{2 0 1 3}$ & $\mathbf{2 0 1 4}$ & $\mathbf{2 0 1 5}$ & $\mathbf{2 0 1 6}$ & $\mathbf{2 0 1 7}$ \\
\hline \multicolumn{10}{|c|}{$\%$ Difference } \\
\hline$(7.0)$ & $(0.1)$ & +1.2 & +3.1 & $(11.3)$ & $(11.8)$ & +13.9 & $(8.5)$ & $(5.7)$ & +6.4 & +2.8 & $(5.5)$ & $(8.0)$ & $(9.7)$ & $(23.0)$ \\
\hline \multicolumn{10}{|c|}{ Standard Deviation to Mean ratio difference (\%) } \\
\hline$(33.9)$ & +27.6 & +66.6 & +68.9 & +81.2 & $(6.2)$ & $(1.0)$ & +32.7 & +12.3 & +116.3 & $(8.6)$ & +7.6 & $(40.2)$ & $(41.4)$ & $(39.1)$ \\
\hline
\end{tabular}




\section{EV/EBIT FAIR VALUES}

As well as the previous multiples, also the EV/EBIT is one of the most commonly used in practice. This multiple (figure 1, horizontal line filled bar) shows great differences if compared with the real market capitalization fair value. In particular, the difference is almost in any case an over-estimation of more than $+10 \%$ up to $+42 \%$. The volatility over the years is also pronounced, with peaks of variations, in particular during the crisis period (from $+11.5 \%$ in 2008 to $+41.7 \%$ in 2009 , then $+17.8 \%$ in 2010 and again up to $+30.3 \%$ in 2011 ). According to our analysis, this multiple is one of the most unreliable of all for the estimation of the portfolio fair value.

Table 8: EV/EBIT-fair-value percent difference from market capitalization and standard deviation to mean ratio difference

\begin{tabular}{|l|l|l|l|l|l|l|l|l|l|l|l|l|l|l|}
\hline $\mathbf{2 0 0 3}$ & $\mathbf{2 0 0 4}$ & $\mathbf{2 0 0 5}$ & $\mathbf{2 0 0 6}$ & $\mathbf{2 0 0 7}$ & $\mathbf{2 0 0 8}$ & $\mathbf{2 0 0 9}$ & $\mathbf{2 0 1 0}$ & $\mathbf{2 0 1 1}$ & $\mathbf{2 0 1 2}$ & $\mathbf{2 0 1 3}$ & $\mathbf{2 0 1 4}$ & $\mathbf{2 0 1 5}$ & $\mathbf{2 0 1 6}$ & $\mathbf{2 0 1 7}$ \\
\hline \multicolumn{10}{|c|}{ \% Difference } \\
\hline+5.3 & +16.2 & +35.1 & +20.0 & +13.7 & +11.5 & +41.7 & +17.8 & +30.3 & +30.8 & +17.8 & +17.0 & +10.0 & +12.9 & $(5.1)$ \\
\hline \multicolumn{10}{|c|}{ Standard Deviation to Mean ratio difference (\%) } \\
\hline$(18.8)$ & +39.6 & +202.4 & +111.3 & +96.3 & +19.8 & $(25.2)$ & +27.2 & +12.4 & +58.5 & $(38.1)$ & $(17.2)$ & $(70.9)$ & $(67.9)$ & $(65.5)$ \\
\hline
\end{tabular}

Source: our processing.

In the case of the EV/EBIT forward multiple (figure 2, horizontal line filled bar), differences are similar to those of the other "forwards". In fact, it results in a consistent underestimation in most of the years, with the same volatility and uncertainty during the crisis period.

Table 9: EV/EBIT-forward-fair-value percent difference from market capitalization and standard deviation to mean ratio difference

\begin{tabular}{|l|l|l|l|l|l|l|l|l|l|l|l|l|l|l|}
\hline $\mathbf{2 0 0 3}$ & $\mathbf{2 0 0 4}$ & $\mathbf{2 0 0 5}$ & $\mathbf{2 0 0 6}$ & $\mathbf{2 0 0 7}$ & $\mathbf{2 0 0 8}$ & $\mathbf{2 0 0 9}$ & $\mathbf{2 0 1 0}$ & $\mathbf{2 0 1 1}$ & $\mathbf{2 0 1 2}$ & $\mathbf{2 0 1 3}$ & $\mathbf{2 0 1 4}$ & $\mathbf{2 0 1 5}$ & $\mathbf{2 0 1 6}$ & $\mathbf{2 0 1 7}$ \\
\hline \multicolumn{10}{|c|}{ \% Difference } \\
\hline$(18.2)$ & $(10.1)$ & $(4.1)$ & $(11.9)$ & $(17.5)$ & $(10.7)$ & +12.8 & $(8.9)$ & $(1.0)$ & +7.4 & $(1.2)$ & $(8.8)$ & $(14.1)$ & $(9.9)$ & $(21.8)$ \\
\hline \multicolumn{10}{|c|}{ Standard Deviation to Mean ratio difference (\%) } \\
\hline$(38.2)$ & +29.8 & +97.4 & +72.5 & +58.9 & $(20.1)$ & $(18.4)$ & +19.6 & +13.8 & +64.0 & $(36.1)$ & $(13.2)$ & $(67.3)$ & $(62.7)$ & $(64.0)$ \\
\hline
\end{tabular}

Source: our processing.

\section{TRANSACTION MULTIPLES (EBITDA) FAIR VALUE}

In line with our results on market multiples, the transaction multiples calculated on EBITDA (figure 1, dark gray with lines fill bar), when available, show low levels of reliability. The values are inconsistent through the years and are greatly fluctuating from almost a half of the market cap value up to more than $30 \%$ greater. This would result in a great artificial volatility in the financial statement, that is, volatility due to estimation errors and not to changing economic conditions.

Table 10: Net EBITDA-Transaction-multiple-fair-value percent difference from market capitalization

\begin{tabular}{|l|l|l|l|l|l|l|l|l|l|l|l|l|l|l|}
\hline $\mathbf{2 0 0 3}$ & $\mathbf{2 0 0 4}$ & $\mathbf{2 0 0 5}$ & $\mathbf{2 0 0 6}$ & $\mathbf{2 0 0 7}$ & $\mathbf{2 0 0 8}$ & $\mathbf{2 0 0 9}$ & $\mathbf{2 0 1 0}$ & $\mathbf{2 0 1 1}$ & $\mathbf{2 0 1 2}$ & $\mathbf{2 0 1 3}$ & $\mathbf{2 0 1 4}$ & $\mathbf{2 0 1 5}$ & $\mathbf{2 0 1 6}$ & $\mathbf{2 0 1 7}$ \\
\hline \multicolumn{10}{|c|}{$\%$ Difference } \\
\hline n.d. & n.d. & n.d. & n.d. & $(20.9)$ & 32.7 & $(1.9)$ & $(19.2)$ & +5.8 & $(22.6)$ & $(48.9)$ & $(44.4)$ & $(44.5)$ & $(34.9)$ & $(48.9)$ \\
\hline \multicolumn{10}{|c|}{ Standard Deviation to Mean ratio difference (\%) } \\
\hline n.d. & n.d. & n.d. & n.d. & +54.6 & +32.9 & +27.6 & +55.8 & $(1.1)$ & $(19.9)$ & $(32.7)$ & +36.2 & $(43.9)$ & $(1.6)$ & +22.0 \\
\hline
\end{tabular}


This volatility is not influenced by the premium applied to the evaluation. The next table reports the transaction multiples gross of the "control premium". Results are consistent with those from the net multiple: low reliability and high volatility. The results of gross EBITDA-Transaction multiple fair value are not reported in the figure, because the Net Transaction (reported as dark gray with lines fill bar) is a mere proportional reduction of the gross value (that, thus, would be even higher than it is for the "Net" multiple).

Table 11: Gross EBITDA-Transaction-multiple-fair-value percent difference from market capitalization

\begin{tabular}{|c|c|c|c|c|c|c|c|c|c|c|c|c|c|c|}
\hline $\mathbf{2 0 0 3}$ & $\mathbf{2 0 0 4}$ & $\mathbf{2 0 0 5}$ & $\mathbf{2 0 0 6}$ & $\mathbf{2 0 0 7}$ & $\mathbf{2 0 0 8}$ & $\mathbf{2 0 0 9}$ & $\mathbf{2 0 1 0}$ & $\mathbf{2 0 1 1}$ & $\mathbf{2 0 1 2}$ & $\mathbf{2 0 1 3}$ & $\mathbf{2 0 1 4}$ & $\mathbf{2 0 1 5}$ & $\mathbf{2 0 1 6}$ & $\mathbf{2 0 1 7}$ \\
\hline n.d. & n.d. & n.d. & n.d. & +21.8 & +104.1 & +50.9 & +24.3 & +62.8 & +19.0 & $(21.4)$ & $(14.4)$ & $(14.7)$ & +0.2 & $(21.4)$ \\
\hline
\end{tabular}

Source: our processing. 
Figure 1: Normalized results for full portfolio - Stock multiples

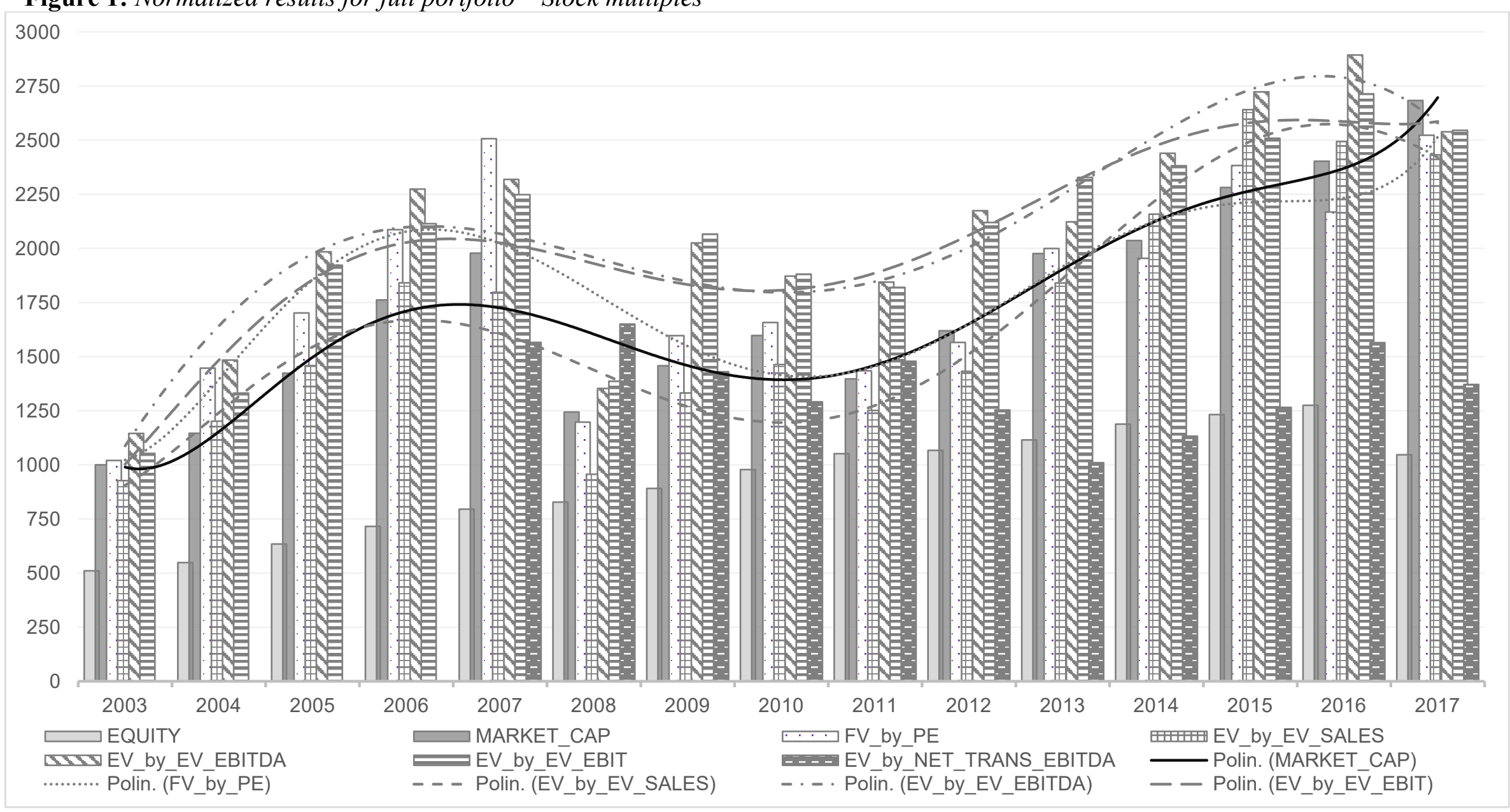

Source: our processing. Equity stands for Book Value of Equity. Market Cap stands for Market capitalization, FV_by_PE is the fair value calculated via the P/E multiple, EV by_EV_* is the enterprise value calculated via the market multiple on the economic item indicated $\left({ }^{*}\right)$ 
Figure 2: Normalized results for full portfolio - Forward multiples

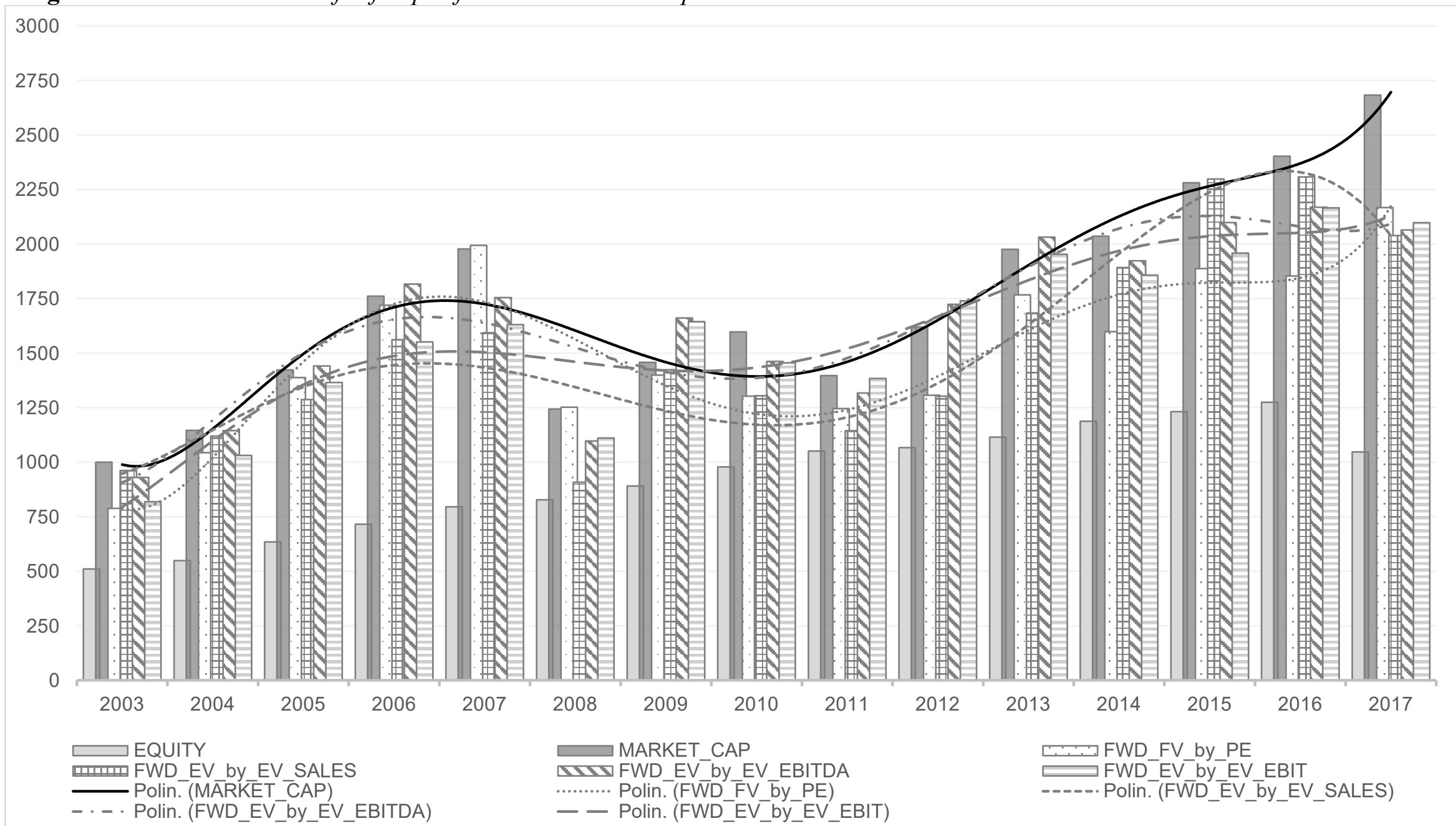

Source: our processing. Equity stands for Book Value of Equity. Market Cap stands for Market capitalization, FV_by_PE is the fair value calculated via the P/E multiple, $E V_{-}$by $E V_{-}^{*}$ is the enterprise value calculated via the market multiple on the economic item indicated (*) 


\subsection{Analysis of the portfolio trends and volatility in the financial statements: estimation}

of the variation of the portfolio evaluation and its effects on P/L statement

The next step of our analysis consists in the appraisal of the effects that the consistent application of the multiples could have on the financial statement, and in particular on the assets and on the earnings, in the case of implementation of the IFRS principles. In fact, differences between the market capitalization and the fair values estimates deploy their effects not only in the year of evaluation but also in the following years. The effect of the errors in a single year shows the over- or under-estimation of the asset value. The variation between two consequent years reflects the error on the profit and losses statement, thus on the earnings. Table 12 shows the variations of the portfolio value for each of the different multiple over time. Such variations have to be compared with the variations in the market capitalization ${ }^{\text {ii }}$.

Table 12: Variations (\%o, per-thousand) of the portfolio value between years

\begin{tabular}{|c|c|c|c|c|c|c|c|c|c|c|c|c|c|c|}
\hline & $\begin{array}{l}2003- \\
2004\end{array}$ & $\begin{array}{l}2004- \\
2005\end{array}$ & $\begin{array}{l}2005- \\
2006\end{array}$ & $\begin{array}{l}2006- \\
2007\end{array}$ & $\begin{array}{l}2007- \\
2008\end{array}$ & 2008- & $\begin{array}{l}2009- \\
2010\end{array}$ & $\begin{array}{l}2010- \\
2011\end{array}$ & $\begin{array}{l}2011- \\
2012\end{array}$ & $\begin{array}{l}2012- \\
2013\end{array}$ & $\begin{array}{l}2013- \\
2014\end{array}$ & $\begin{array}{l}2014- \\
2015\end{array}$ & $\begin{array}{l}2015- \\
2016\end{array}$ & $\begin{array}{l}\text { 2016- } \\
2017\end{array}$ \\
\hline Equity & 37.9 & 85.9 & 80.9 & 80.2 & 32.1 & 63.2 & 87.2 & 72.9 & 15.41 & 48.7 & 72.7 & 44.0 & 38.0 & 85.9 \\
\hline Market cap & 145.9 & 277.2 & 338.3 & 216.2 & (734.1) & 214.3 & 139.4 & (200.1) & 222.4 & 356.3 & 60.3 & 244.9 & 121.5 & 280.3 \\
\hline $\mathrm{P} / \mathrm{E}$ & 426.9 & 254.7 & 384.9 & 420.6 & $(1309.5)$ & 399.2 & 60.7 & $(222.6)$ & 131.1 & 433.5 & $(45.3)$ & 428.8 & $(215.0)$ & 354.9 \\
\hline $\mathrm{P} / \mathrm{E}$ fwd & 255.5 & 344.2 & 331.8 & 274.7 & $(742.2)$ & 147.1 & (96.8) & $(56.9)$ & 61.3 & 460.2 & $(168.5)$ & 289.1 & $(34.1)$ & 313.6 \\
\hline $\mathrm{EV} / \mathrm{sales}$ & 274.4 & 256.8 & 382.8 & (43.9) & $(840.2)$ & 375.4 & 131.3 & $(212.3)$ & 181.0 & 408.1 & 317.8 & 482.6 & $(146.6)$ & $(62.2)$ \\
\hline $\mathrm{EV} /$ sales fwd & 157.7 & 167.9 & 273.8 & 32.3 & $(685.3)$ & 515.8 & (119.5) & $(160.4)$ & 158.4 & 381.4 & 208.5 & 405.8 & 9.9 & (268.8) \\
\hline EV/EBITDA & 338.6 & 500.1 & 289.9 & 45.0 & (965.6) & 671.7 & $(152.8)$ & $(27.9)$ & 329.9 & $(51.7)$ & 317.0 & 283.3 & 170.7 & $(355.0)$ \\
\hline EV/EBITDA fwd & 214.7 & 295.9 & 376.0 & $(62.2)$ & $(657.6)$ & 564.1 & (199.2) & $(144.5)$ & 406.4 & 308.1 & $(108.2)$ & 174.8 & 70.8 & (104.3) \\
\hline EV/EBIT & 279.0 & 590.6 & 191.3 & 134.2 & $(861.1)$ & 679.1 & (184.7) & $(61.2)$ & 299.2 & 208.4 & 54.2 & 126.8 & 205.0 & $(168.4)$ \\
\hline EV/EBIT fwd & 212.4 & 334.7 & 186.0 & 79.4 & $(519.8)$ & 533.1 & $(188.9)$ & (71.6) & 356.0 & 213.4 & $(95.3)$ & 101.2 & 207.1 & $(68.0)$ \\
\hline Net Trans. EBITDA & & & & & 84.8 & $(219.7)$ & (139.4) & 187.3 & (225.1) & (243.6) & 122.8 & 133.0 & 298.7 & (193.1) \\
\hline
\end{tabular}

Source: our processing.

Figure 3 shows the over- or under-estimation of the portfolio variations, thus the extraprofit or loss due just to the different method of fair value measurement. Namely, it shows the variation in the fair value calculated by each multiple that exceeds the variation of the market capitalization. This should eliminate the intrinsic volatility of the enterprises in the portfolio, by showing the extra-profits or extra-losses not related to market risk factors (comprised in the fluctuations of market capitalizations) but caused by the mere usage of the evaluation method.

In particular, the EBIT(DA) based historical multiples show a high level of unreliability, with great over- and under-estimations almost never lower than $\pm 10 \%( \pm 100 \%)$. The P/E multiple, due to the great volatility, shows peaks of variation during peculiar economic conditions, such as the market turmoil of 2007-2009. The EV/sales multiple shows great volatility during the economic recovery period (2013-2017), but it seems to be less sensitive to crises and stagnations and more conservative. The transaction multiples has a great volatility and thus a high unreliability with overestimations in most cases greater than $+20 \%$ and underestimation lower than $-20 \%( \pm 200 \%)$.

The forward counterparts of each multiple show more or less the same fluctuations, just a bit more moderate than the "historical" ones. Nevertheless, this moderation in the fluctuations goes along with the unreliability described in the previous section, where the values are in most cases lower than the market capitalization. Taken as a whole, forward multiples provide more conservative results. 
Figure 3: Surplus of profit/losses (per-thousand) by applying the historical market multiples

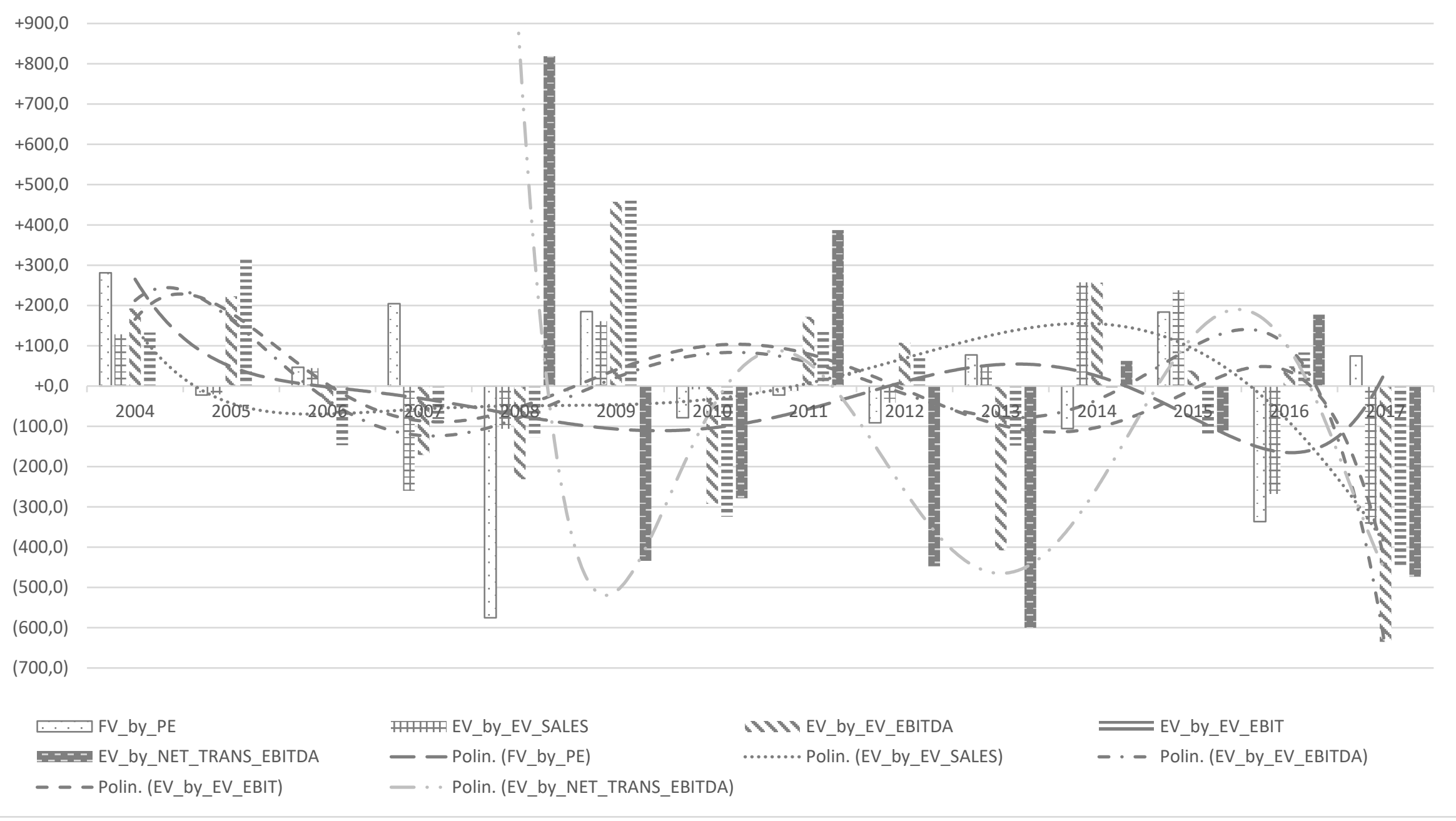

Source: our processing. Equity stands for Book Value of Equity. Market Cap stands for Market capitalization, FV_by_PE is the fair value calculated via the P/E multiple, $E V$ by $E V *$ is the enterprise value calculated via the market multiple on the economic item indicated (*) 


\section{Figure 4: Surplus of profit/losses (per-thousand) by applying the forward market multiples}

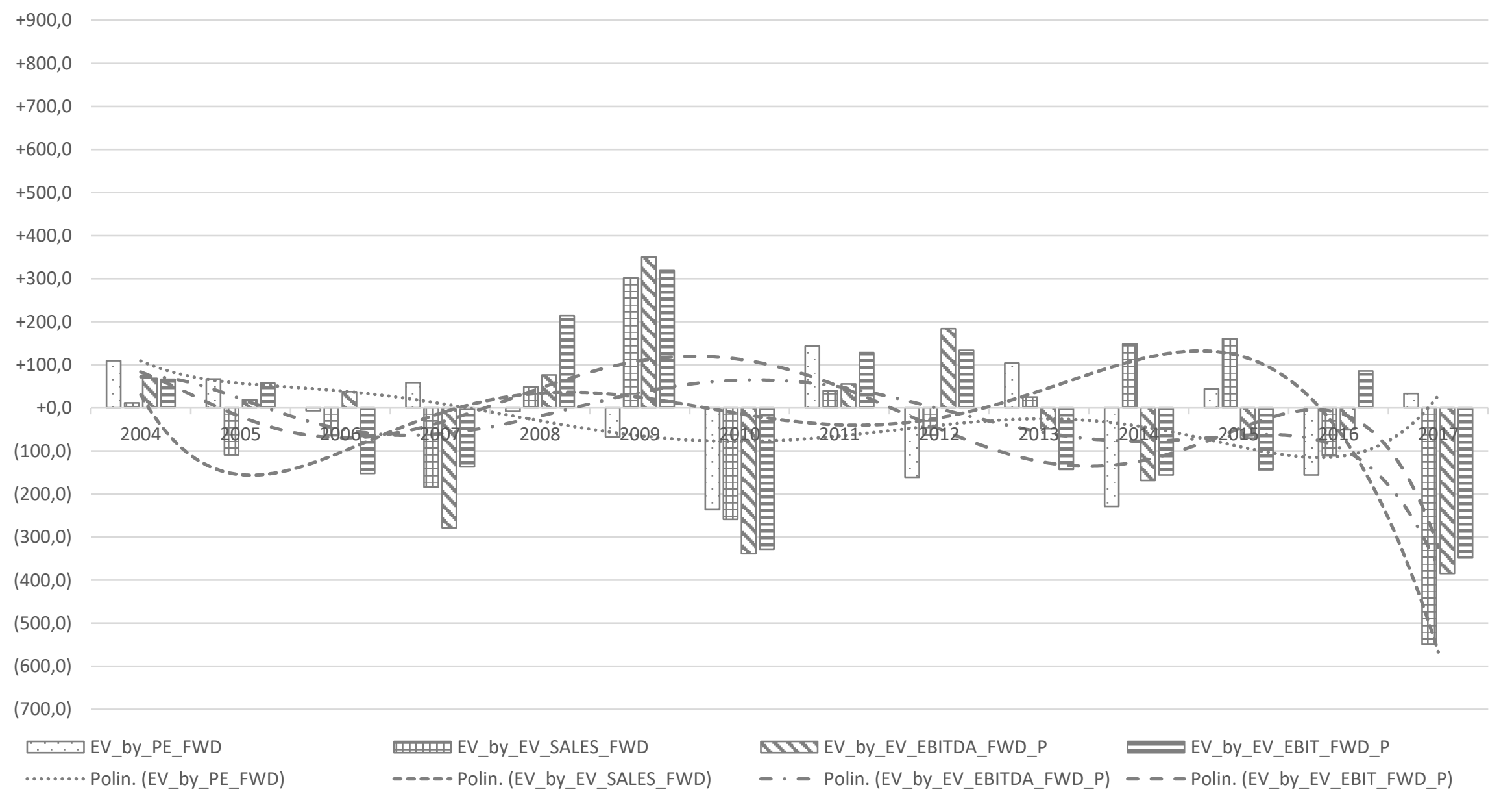

Source: our processing. Equity stands for Book Value of Equity. Market Cap stands for Market capitalization, FV by PE is the fair value calculated via the P/E multiple, EV_by_EV_*is the enterprise value calculated via the market multiple on the economic item indicated (*) 


\subsection{Descriptive statistics and distribution of the estimated-to-real fair value ratios}

In order to investigate whether the differences between the portfolio real and estimated values are statistically significant, we focus on the distribution of the ratios. Accordingly, we calculate the ratio between the estimated value and the market capitalization for each company and for each year.

As reported in appendix D, the first quartile of the Market Multiples to Market Cap ratios distributions range around a value of $0.60-0.70$. This implies that, at single company level, market multiples estimate a fair value that is more or less $30 \%$ to $40 \%$ lower than the actual market capitalization. The median of the ratio stands in a 0.9-1.5 range. This means that in half of the cases it is higher than a 1:1 ratio. In more than the $75 \%$ of the cases, the market multiples at a single-company level are not even close to the real fair value.

Furthermore, estimates distribution has a right tail (skewness greater than 0 ) and that the values concentrate greatly around the mean, which is greater than 1.30 in most cases. This means that, in most of the single company estimations of fair values, the market multiples return a result that is greater than 1 and on average $30 \%$ higher.

As for the forward multiples, the first quartile and the median are much lower than the historical multiple, which is consistent with the results found at portfolio level, where the fair value of the portfolio calculated with $\mathrm{P} / \mathrm{E}$ forward is mostly lower than the market capitalization. By looking at single periods, results are consistent with previous analysis. The standard deviation at period level varies greatly, showing that there is a large volatility in the application of the technique, even at a single-company level.

\section{Comments and conclusions}

In day-to-day life, both practitioners tend to use the market and transaction multiples in the estimation of the fair value of private equities.

In order to test the reliability of fair value estimates based on market and transaction multiples in measuring fair values, we have considered a sample of public companies, which we have treated as if they were private. We have therefore assessed their fair value by using Level 2 inputs. We have used market capitalization as their real fair value, which is consistent with the market efficiency hypothesis (Fama, 1970). We have then compared fair value estimates based on transaction and market multiples with market capitalization to test for estimation errors.

Our results are consistent with previous research and show that market multiples introduce great estimation errors in assessing the fair value of private equities. More specifically, the results of our analysis, which have been conducted on data from over 1500 companies over 15 years, show that none of the market multiples is capable of appraising the real market value of a portfolio except in just a few single cases. The use of forecasted ("forward"), rather than historical multiples slightly improves the performance of some of the multiples, in particular for the P/E multiple, which is consistent with Lie \& Lie (2002). Nonetheless, this improvement does not hold during market crises and high-volatility periods.

Moreover, such an inconsistency and unreliability generates economic effects both in the year of measurement and in the following years, with a surplus of profits/losses that tend to be greater than those of market capitalization. In more than three out of four cases, market multiples at single-company level greatly underestimate or overestimate the real fair value, and in more than half of the cases the measurement overestimates it. The unreliability of market multiples is particularly exacerbated in the case of EBITDA and EBIT. 
Our analysis is slightly limited for the transaction multiples in the years 2010 and 2014, because in some portfolios and in some years it is not possible to calculate a transaction multiple. Also in this case, however, there is compelling evidence that transaction multiples do not provide reliable fair value estimates either.

Taken as a whole, our results suggest that market and transaction multiples probably do not catch firm-specific risk factors that affect the actual fair value of the firm, as reflected in market capitalization. Indeed, the use of mean and median for market multiples calculated for each industry tend to elide the idiosyncratic component of risk. Along the same lines, transaction multiples incorporate expectations related to specific transactions, which may be not applicable to others.

Such issues should be carefully taken into consideration by regulators. The risk is that fair value estimates based on transaction and market multiples may mislead investors in perceiving the financial data as highly reliable. Therefore, evidence on this point is of direct interest to accounting policymakers since the explicit purpose of the EU Regulation $1606 / 2002$, which has introduced the IAS/IFRS accounting system in the EU, is to ensure a high degree of transparency and comparability in financial statements as well as the efficient functioning of the capital markets.

\section{Appendix}

The appendix is stored in a separate document. The related file can be found at the following permanent link: https://goo.gl/hsjteC.

\section{References}

Aboody, D., Barth, M. E., \& Kasznik, R. (2006). Do firms understate stock option-based compensation expense disclosed under SFAS 123? Review of Accounting Studies, 11(4), 429-461. https://doi.org/10.1007/s11142-006-9013-0

Baiman, S., \& Verrecchia, R. E. (1996). The relation among capital markets, financial disclosure, production efficiency, and insider trading. Journal of Accounting Research, 34(1), 1-22. https://doi.org/10.2307/2491329

Barth, M. E., Beaver, W. H., \& Landsman, W. R. (2001). The relevance of the value relevance literature for financial accounting standard setting: Another view. Journal of Accounting and Economics, 31(1-3), 77-104. https://doi.org/10.1016/S0165-4101(01)00019-2

Bartov, E., Mohanram, P., \& Nissim, D. (2007). Managerial discretion and the economic determinants of the disclosed volatility parameter for valuing ESOs. Review of Accounting Studies, 12(1), 155-179. https://doi.org/10.1007/s11142-006-9024-x

Bens, D. A., \& Monahan, S. J. (2004). Disclosure quality and the excess value of diversification. Journal of Accounting Research, 42(4), 691-730. https://doi.org/10.1111/j.1475679X.2004.00154.X

Biddle, G. C., \& Hilary, G. (2006). Accounting quality and firm-level capital investment. Accounting Review, 81(5), 963-982. https://doi.org/10.2308/accr.2006.81.5.963

Bushman, R. M., \& Smith, A. J. (2001). Financial accounting information and corporate governance. Journal of Accounting and Economics, 32(1-3), 237-333. https://doi.org/10.1016/S01654101(01)00027-1

Cochrane, J. H. (2005). The risk and return of venture capital. Journal of Financial Economics, 75(1), 3-52. https://doi.org/10.1016/j.jfineco.2004.03.006

Diamond, D. W., \& Verrecchia, R. E. (1991). Disclosure, Liquidity, and the Cost of Capital. The Journal of Finance, 46(4), 1325-1359. https://doi.org/10.1111/j.1540-6261.1991.tb04620.x

Fama, E. F. Efficient Capital Markets: A Review of Theory and Empirical Work. The Journal of

Finance, Vol. 25 (2), 383-417, https://doi.org/10.2307/2325486

Goh, B., Ng, J., \& Yong, K. (2009). Market Pricing of Banks' Fair Value Assets Reported Under SFAS 157 During the 2008 Economic Crisis. Market pricing of banks' fair value assets reported under SFAS 157 during the 2008 economic crisis.

Hope, O.-K., \& Thomas, W. B. (2008). Managerial empire building and firm disclosure. Journal of Accounting Research, 46(3), 591-626. https://doi.org/10.1111/j.1475-679X.2008.00289.x

International Accounting Standards Board. Fair Value Measurement, Pub. L. No. IFRS 13 (2013). 
Kanodia, C., Sapra, H., \& Venugopalan, R. (2004). Should Intangibles Be Measured: What Are the Economic Trade-Offs? Journal of Accounting Research, 42(1), 89-120. https://doi.org/10.1111/j.1475-679X.2004.00130.x

Kim, M., \& Ritter, J. R. (1999). Valuing IPOs. Journal of Financial Economics, 53(3), 409-437. https://doi.org/10.1016/S0304-405X(99)00027-6

Kolev, K. (2009). Do Investors Perceive Marking-to-model as Marking-to-myth? Do investors perceive marking-to-model as marking-to-myth?

Lie, E., \& Lie, H. J. (2002). Multiples Used to Estimate Corporate Value. Financial Analysts Journal, 58(2), 44-54. https://doi.org/10.2469/faj.v58.n2.2522

Lombardo, D., \& Pagano, M. (2002). Law and equity markets: A simple model. Corporate Governance Regimes: Convergence and Diversity, 343-362.

Moskowitz, T. J., \& Vissing-Jørgensen, A. (2002). The returns to entrepreneurial investment: A private equity premium puzzle? American Economic Review, 92(4), 745-778. https://doi.org/10.1257/00028280260344452

Palea, V., \& Maino, R. (2013). Private equity fair value measurement: A critical perspective on ifrs 13. Australian Accounting Review, 23(3), 264-278. https://doi.org/10.1111/auar.12018

Quigley, J. M., \& Woodward, S. E. (2002). Private Equity before the Crash: Estimation of an Index. Private equity before the crash: Estimation of an index (Working Paper).

Song, C. J., Thomas, W. B., \& Yi, H. (2010). Value relevance of FAS No. 157 Fair Value hierarchy information and the impact of corporate governance mechanisms. Accounting Review, 85(4), 1375-1410. https://doi.org/10.2308/accr.2010.85.4.1375

Svantner, A., Conti, P. A., \& Eyerman, E. (2016). European Leveraged Finance Multiple EV-aluator (Special Report). FitchRatings. https://www.fitchratings.com/site/dam/jcr:0d840fdc-9163-49a1-ab68dcb3034265b4/European\%20Leveraged\%20Finance\%20Multiple\%20EV-aluator.pdf

\footnotetext{
${ }^{\mathrm{i}}$ As the difference is not significant, the robustness check is not tabled.

ii The variation is scaled by considering the market capitalization of year 2003 equal to 1000 . Thus, the variations reported in the table is a "per thousand" result.
} 